jeans and a baseball hat, and offered to ring for a taxi. We accepted the offer.

If we had known that our daughter would be subjected to such treatment, would we have taken a different route? Yes. Do we, and she, now regret not having done so? No. It had been a deeply unpleasant experience, but it is the sort of experience which many Palestinians, going about their daily lives, suffer routinely. Except they have no passports, no embassy to call, and no guarantee of eventual release. Gaining even a little insight into what that might feel like was invaluable and helped to make some sense of the personal stories behind the Palestine and Israel headlines more real.

\section{Lesley Morrison}

DOI: 10.3399/bjgp09X420158

\title{
Caveat emptor
}

The approval by the European Union for 'over-the-counter' (OTC) sale of the antiobesity drug orlistat (under the trade name alliø) has provoked another round of the familiar controversy over any attempt to reduce the medical profession's monopoly over the supply of drugs. Only a few weeks earlier there was a similar furore over pilot projects to make the oral contraceptive pill available without prescription in pharmacies.

To me - and I believe to many doctors - proposals to relax 'prescription-only' regulations seem eminently sensible. These drugs are essentially 'lifestyle' medications with clearly defined indications and wide margins of safety. If patients could get such drugs in pharmacies it would be more convenient for them and it would take some pressure off our already overburdened surgeries.

Yet some doctors are reluctant to forgo the opportunity for moralising health promotion that is offered by any request for a prescription in the surgery. An editorial on orlistat in the Lancet complained that patients would miss out on the 'holistic approach necessary in the management of all obese patients'. It neglected to mention that there is even less evidence of the efficacy of its preferred approach - 'long-term lifestyle changes' - than there is for taking orlistat.

In a 'head to head' debate on the OTC contraceptive pill in the BMJ, the women's health spokesperson of the RCGP was concerned that young women would evade evangelical GPs offering longacting reversible contraception (such as coils, injections and implants) in the crusade to deter teenage pregnancy. ${ }^{2}$ Leaving aside the question of whether GPs should involve themselves in a Malthusian campaign with distinctly eugenic undertones, the fact that the large majority of users of oral contraception are not teenagers was entirely ignored.

Now that the project of replacing capitalism with a more rational and equitable system of production - to which I devoted much time and energy in the past - is off the agenda and the market is the only show in town, its advocates are remarkably lacking in confidence in its mechanisms. This is dramatically evident in recent state intervention in the financial system, and it is also apparent in the relations between the NHS and the pharmaceutical industry, where market principles are distorted by monopoly and cartel, price-fixing and public subsidy, and an opaque regulatory framework.

Not only is there great resistance to making drugs available OTC, there is also fierce hostility to allowing direct advertising of pharmaceuticals to the public. But this simply reflects a combination of contempt for the capacity of people to make their own judgements about the value of medications and a paternalistic notion of protecting vulnerable consumers from the rapacious pharmaceutical corporations. One result of the excessive regulation of this area is the proliferation of 'disease-mongering' advertisements, with which drug companies 'raise awareness' of conditions from athlete's foot to erectile dysfunction, in the hope of luring patients into our surgeries to request the appropriate product.

Why not let the drug companies freely advertise these medications and the pharmacies sell them? Customers could then make their own choices and, in the ancient spirit of 'buyer beware', look out for the adverse effects. If people believe that dieting aids and birth control pills, or vitamins and Viagra, or statins and SSRIs, are a good bargain, let them buy them, just as they buy paracetamol and aspirin, beer and cigarettes, or any other commodity.

Those of us who consider that medical practice should be about the diagnosis and treatment of disease, rather than the regulation of lifestyles (with or without the aid of pharmaceuticals), would then have more time to get on with our work.

\section{REFERENCES}

1. Over-the-counter medicines: in whose best interests? Lancet 2009; 373: 354.

2. Should the contraceptive pill be available without prescription? BMJ 2009; 338: 202-203. http://www.bmj.com/cgi/section_pdf/337/dec23 2/a3044.pdf (accessed 3 Feb 2009).

DOI: 10.3399/bjgp09X420167 